\title{
Erratum to: NACP-Rep1 relates to Beck Depression Inventory Scores in Healthy Humans
}

\author{
Bernd Lenz • Christiane Sysk • Norbert Thuerauf • \\ Marion Clepce • Karin Reich • Helge Frieling • \\ Georg Winterer • Stefan Bleich • Johannes Kornhuber
}

Published online: 14 March 2013

(C) Springer Science+Business Media New York 2013

\section{Erratum to: J Mol Neurosci (2011) 44:41-47 DOI 10.1007/s12031-011-9493-7}

A reanalysis of the NACP-Rep1 genotypes in our publication "NACP-Rep1 relates to Beck Depression Inventory scores in healthy humans" (Lenz et al. 2011) revealed a deviation from the principles of the HardyWeinberg equilibrium (HWE, goodness-of-fit test $\left[\chi^{2}\right]$, $\mathrm{p}<10^{-30}$ ). As reported in literature, several factors might cause violations of HWE. For the NACP-Rep1 polymorphism, a deviation from HWE is not uncommon. In their collaborative analysis, Maraganore et al. (2006) excluded genotype data from 3 of 18 study sites because the NACP-Rep1 genotype frequencies deviated from HWE.

The online version of the original article can be found at http://dx.doi.org/ 10.1007/s12031-011-9493-7.

B. Lenz $(\bowtie) \cdot$ C. Sysk $\cdot$ N. Thuerauf $\cdot$ M. Clepce $\cdot$ K. Reich $\cdot$

H. Frieling $\cdot$ S. Bleich $\cdot$ J. Kornhuber

Department of Psychiatry and Psychotherapy,

Friedrich-Alexander-University of Erlangen-Nuremberg,

Schwabachanlage 6-10,

91054 Erlangen, Germany

e-mail: bernd.lenz@uk-erlangen.de

H. Frieling $\cdot$ S. Bleich

Department of Psychiatry, Social Psychiatry and Psychotherapy,

Hannover Medical School, Hannover, Germany

G. Winterer

Cologne Center for Genomics (CCG), University of Cologne,

Cologne, Germany
Different reasons might account for the excess of homozygotes in our sample. Keeping in mind that the polymorphism represents a mixed sequence repeat (Xia et al. 1996), fragments with the same length in sequence analysis might represent heterozygous alleles, possibly resulting in an overestimation of homozygous individuals. However, the strong deviation from HWE in our study signaled a genotyping artifact. Therefore, we regenotyped a subsample of individuals to validate our previous results (new primer pair: forward $5^{6}$-TAT TTT GAC CTT TGT TTT GGC-3‘, reverse 5'FAM-TTT ATG TAT TTT ATT CCC TGG C-3'; $0.25 \mu$ l forward primer, $0.25 \mu \mathrm{l}$ reverse primer [each $20 \mu \mathrm{M}$ ], $5 \mu \mathrm{l}$ HotStarTaq Master Mix [Qiagen, Hilden, Germany], $4 \mu \mathrm{H}_{2} \mathrm{O}$ and $0.5 \mu \mathrm{l}$ DNA template; PCR conditions $1 \times 95{ }^{\circ} \mathrm{C} 15 \mathrm{~min}$, $40 \times 95{ }^{\circ} \mathrm{C} 30 \mathrm{~s}, 50{ }^{\circ} \mathrm{C} 30 \mathrm{~s}, 72{ }^{\circ} \mathrm{C} 30 \mathrm{~s}, 1 \times 72{ }^{\circ} \mathrm{C}$ $15 \mathrm{~min})$.

The results revealed initial misgenotyping primarily due to an overestimation of homozygous individuals. We recalculated the previously described statistical analyses using corrected genotype frequencies (Lenz et al. 2011). The corrected genotypes were in HWE $(p=0.12)$. Both the non-parametric correlation analysis and the linear regression analysis showed significant positive associations between mean NACP-Rep1 and the BDI score $(\mathrm{n}=213$; Spearman's $\rho=0.136, p=0.048 ; \mathrm{B} \pm \mathrm{SD}, 0.424 \pm 0.195$, beta $=0.148$, $\mathrm{T}=2.178, \mathrm{p}=0.031$; model summary: $\mathrm{R}=0.148, \mathrm{R}^{2}=0.022$, adjusted $\mathrm{R}^{2}=0.017$; ANOVA, $\mathrm{F}=4.743, \mathrm{p}=0.031$ ). Subsequently, we divided the group into three subgroups according to the additive repeat length (Bönsch et al. 2005). Short: $265 / 267(n=8), 265 / 269(n=3), 267 / 267$ $(n=19)$; intermediate: $265 / 271 \quad(n=3), 267 / 269(n=74)$, 
267/271 (n=11), 269/269 ( $\mathrm{n}=75)$; long: 269/271 ( $\mathrm{n}=16)$, $271 / 271(n=4)$. The subgroups differed significantly in terms of the BDI score (Kruskal-Wallis test; $\chi^{2}=8.096$, $\mathrm{df}=2, \mathrm{p}=0.017$ ).

In summary, we corrected the previous misgenotyping and also found significant associations between the length of the NACP-Rep1 polymorphism and the BDI score in the corrected data set.

Acknowledgments We thank Dr. C. Harker Rhodes (Professor of Pathology and Neurology, Dartmouth-Hitchcock Medical Center, New Hampshire, USA) for his assistance.

\section{References}

Bönsch D, Lederer T, Reulbach U, Hothorn T, Kornhuber J, Bleich S (2005) Joint analysis of the NACP-REP1 marker within the alpha synuclein gene concludes association with alcohol dependence. Hum Mol Genet 14:967-971

Lenz B, Sysk C, Thuerauf N et al (2011) NACP-Rep1 relates to Beck Depression Inventory scores in healthy humans. J Mol Neurosci 44:41-47

Maraganore DM, de Andrade M, Elbaz A et al (2006) Collaborative analysis of alpha-synuclein gene promoter variability and Parkinson disease. JAMA 296:661-670

Xia Y, Rohan de Silva HA, Rosi BL et al (1996) Genetic studies in Alzheimer's disease with an NACP/alpha-synuclein polymorphism. Ann Neurol 40:207-215 